\title{
Adaptação de um Questionário de Autoconfiança Relacionado a Situações-problema em Odontopediatria ${ }^{1}$
}

\author{
Camila Lima Nascimento \\ Cecília Guarnieri Batista ${ }^{2}$ \\ Gustavo Sattolo Rolim \\ Renata Salvitti de Sá Rocha \\ Antonio Bento Alves de Moraes \\ Universidade Estadual de Campinas
}

\begin{abstract}
RESUMO - É relatada a adaptação do questionário de Milgrom sobre autoconfiança e formas de lidar frente a situaçõesproblemas em odontopediatria. A adaptação foi aprovada por especialistas e analisada em termos da quantidade, coerência e qualidade das respostas suscitadas. Considerou-se o questionário como instrumento que pode contribuir para a formação do odontólogo.
\end{abstract}

Palavras-chave: Psicologia da Saúde, Psicologia Aplicada a Odontologia, relação profissional paciente.

\section{Adaptation of a Self-confidence Questionnaire Pediatric Dental Treatment}

\begin{abstract}
This work describes the adaptation of Milgrom's questionnaire on self-confidence and ways of dealing with behavior problems faced during pediatric dental treatment. The adaptation of the instrument was approved by experts and was analyzed in terms of quantity, coherence and quality of responses. The results of this study suggest that the questionnaire can contribute to dentist's education.
\end{abstract}

Keywords: Health psychology, applied psychology, dentistry, professional patient relationship.

Durante o atendimento odontopediátrico, são freqüentes as situações em que a criança não colabora com o dentista, dificultando ou impedindo o tratamento. Essas ações da criança afetam o desempenho do profissional e, consequentemente, a qualidade do atendimento. A escolha e o uso de estratégias para obter a colaboração da criança dependem das informações a que o profissional teve acesso, principalmente durante a sua graduação, e, por isso, é importante que o curso de graduação aborde essas estratégias em um momento adequado para a formação do profissional. (Issáo \& Guedes, 1999; Wright, 2000; Newton \& Sturmey, 2003; Cardoso, Loureiro \& Nelson-Filho, 2004).

Tendo em vista a freqüência das situações de não-colaboração e a necessidade do profissional lidar com elas, considera-se necessária uma análise da avaliação, feita pelos próprios alunos de odontologia, em relação à sua percepção de habilidades para lidar com as questões relativas à colaboração de crianças durante o atendimento. Essa auto-avaliação permite uma reflexão sobre as condições em relação às quais os estudantes verbalizam dificuldades, apontando para aspectos a serem abordados em sua formação.

Uma das formas de realizar essa avaliação foi proposta por Peter Milgrom, um pesquisador norte-americano que atua no Department of Dental Public Health Sciences da Univer-

1 Apoio: Projeto Temático FAPESP (2006/55986-4)

2 Endereço para correspondência: Unicamp - Faculdade de Ciências Médicas - Departamento de Desenvolvimento Humano e Reabilitação/ Cepre. Rua Tessália Vieira de Camargo, 126. Campinas, SP. CEP: 13083-887. Fone: (019) 3521-8800. Email: cecigb@fcm.unicamp.br sity of Washington, na área de estudos de ansiedade, medo e estratégias de ensino em Odontologia (Milgrom, Weistein \& Getz, 1995). Esse autor elaborou um questionário com 20 questões, descrevendo situações-problema no atendimento odontológico de crianças não-colaboradoras, a ser respondido por odontólogos ou por estudantes de Odontologia. O respondente recebia duas tarefas por situação-problema: (1) indicar seu grau de autoconfiança para atuar em cada situação descrita, em uma escala Likert com 10 pontos; e (2) descrever a forma como atuaria diante da situação-problema apresentada.

O questionário foi apresentado pelo prof. Milgrom para o responsável por disciplinas centradas nas relações interpessoais no atendimento odontológico, de uma universidade pública da região sudeste do Brasil. O questionário foi traduzido e aplicado a um grupo de estudantes de Odontologia. Com base na análise dos resultados encontrados por Ambrosano e Moraes (1999) para essa primeira versão, foi proposta uma reestruturação do questionário para o contexto brasileiro.

\section{Método}

\section{Participantes}

O questionário foi aplicado a uma turma de 70 alunos de Odontologia, que tinham experiência de atendimento em Odontopediatria. O projeto foi submetido e aprovado pelo Comitê de Ética da Faculdade em questão, e os respondentes assinaram o Termo de Consentimento Livre e Esclarecido. 


\section{Instrumento}

A nova versão do questionário apresenta as seguintes características: (1) Utilização de escala Likert de 1 a 7 pontos (e não de 10, como na versão original), para resposta à primeira tarefa da questão; (2) Fixação do número de questões em 10, valor considerado adequado para obter a colaboração dos respondentes, com base em experiências anteriores com questionários dessa natureza (Ambrosano \& Moraes, 1999; Moraes, Batista, Lombardo, Horino, \& Rolim, 2006); (3) Reelaboração do texto de cada questão, para atender aos seguintes requisitos: atribuição de nomes usuais na população brasileira para as crianças; balanceamento das características das crianças, em termos de gênero e faixa etária, de forma a representar equitativamente essas características; escolha de situações representativas das diferentes rotinas odontológicas (entrada, anestesia infiltrativa, restauração, entre outras); escolha de situações representativas do tipo de procedimento odontológico (mais ou menos invasivo) e do tipo de reação de recusa da criança (desde recusa verbal até choro e reações físicas). Essa versão é apresentada na Tabela 1.

A versão apresentada na Tabela 1 foi examinada por quatro especialistas (dois psicólogos e dois odontopediatras, todos atuantes em pesquisa na interface Psicologia e Odontologia), em seus aspectos formais e de conteúdo, e considerado apropriado e representativo das diferentes situações-problema no atendimento odontopediátrico.

Como parte da análise da adequação da presente versão, foi feito um exame detalhado de 10 respostas a cada uma das questões, com seleção aleatória de questionários para cada questão. Essa seleção foi feita sem reposição, até se esgotarem os questionários, e retomada para a análise das questões remanescentes. Assim, foram assim analisadas 100 respostas aos questionários (10 respostas por questão, num total de 10 questões), envolvendo os seguintes aspectos: (1) quantidade de respostas; (2) coerência das respostas; (3) qualidade das respostas.

Tabela 1. Questionário de avaliação de habilidades para lidar com crianças no atendimento odontológico.

Avaliação de habilidades para lidar com crianças no atendimento odontológico

Para cada questão responda:

Meu nível de autoconfiança para esta situação é de $\underline{1234567}$

1 - Considero que minhas habilidades são inadequadas. Não acho que seria capaz de lidar com esse tipo de comportamento desse paciente;

4 - Considero que minhas habilidades nem sempre são adequadas. Acho que sou capaz de lidar com esse comportamento na metade das vezes em que ocorre;

7 - Considero que minhas habilidades são adequadas. Sou capaz de lidar esse tipo de comportamento sempre que ele ocorra.

Após cada questão, descreva como você lidaria com as situações apresentadas.

1. Marcos de 4 anos entra no consultório com você, mas rejeita seu convite para sentar-se na cadeira, silenciosamente balança sua cabeça de um lado para o outro.

2. Gloria, 6 anos, segura sua mão repetidamente na tentativa de forçá-lo a parar de "contar seus dentes" com seu espelho e sonda.

3. Bruno, 8 anos, chora alto quando você está prestes a preparar o seu dente com o motor de alta rotação.

4. Alex, 4 anos, tapa a boca com a mão na cadeira quando percebe que você está prestes a iniciar a restauração.

5. Amanda, 6 anos, da tapas e chutes quando percebe que você está prestes a dar-lhe uma injeção.

6. Júlia, 4 anos, tapa a boca com as mãos quando ela percebe que você está prestes a aplicar-lhe a anestesia tópica.

7. Mariana, 8 anos, começa a esforçar-se para vomitar quando você está realizando moldagem

8. Gabriela, 6 anos, move sua cabeça enquanto você tenta colocar o isolamento absoluto

9. Jorge, 8 anos, tenta sair da cadeira enquanto você tira radiografias.

10. Frederico, 6 anos, agarra sua mão repetidamente na tentativa de forçá-lo a parar de polir uma restauração de amálgama. 


\section{Resultados e Discussão}

Em relação ao primeiro item, verificou-se que, nos 10 questionários analisados, $99 \%$ das questões foram respondidas. Acrescente-se que o exame geral dos 70 questionários indicou que a grande maioria dos estudantes respondeu a todas as questões, e que foram poucos os casos em que alguma questão foi deixada em branco, não se observando rejeição seletiva de nenhuma questão.

Quanto ao segundo item, a análise de coerência baseou-se no conjunto de traços propostos por Koch e Travaglia (2004), a saber: "a possibilidade de estabelecer um sentido para o texto", devendo a coerência "ser entendida como um princípio de interpretabilidade, ligada à inteligibilidade do texto, numa situação de comunicação, e à capacidade que o receptor tem para calcular o sentido desse texto" (p. 21). Os autores dizem ainda que "para haver coerência, é preciso que haja a possibilidade de estabelecer no texto alguma forma de unidade ou relação entre seus elementos" (p. 21-22).

No caso do presente questionário, a coerência foi analisada com base na seguinte pergunta e respectivos critérios de avaliação: $O$ texto da resposta é coerente com a pergunta? Foram previstas as seguintes opções: (a) Sim, a resposta responde à pergunta, pois apresenta uma ou mais soluções no sentido de obter colaboração da criança para a etapa do tratamento descrita na questão; (b) Sim, a resposta responde à pergunta, pois expressa sentimentos do respondente sobre a situação apresentada na questão; (c) Sim, a resposta responde à pergunta, pois o respondente declara-se incompetente diante da situação apresentada (e essa é uma resposta coerente com a pergunta); e (d) Não, a resposta não responde à pergunta, pois o respondente fala sobre outros temas, que não o abordado na questão, a saber: modos de obter colaboração para a etapa do tratamento descrita na questão.

Considerou-se que as alternativas a, b, c indicariam coerência nas respostas, e a alternativa d indicaria incoerência do respondente. Caso fossem detectadas muitas respostas do tipo d, este seria um indicador de má formulação do questionário, em relação à população para a qual foi elaborado. A análise indicou que todas as respostas analisadas foram classificadas como a, b ou c, indicando $100 \%$ de coerência nas respostas.

Quanto ao item 3, relativo à qualidade da resposta, foram propostos os seguintes critérios: (a) Resposta que explicita ações, com algum detalhamento (ex: "Eu acalmaria a criança, falando com ela que não vai doer"); (b) Resposta que explicita seqüência de ações, em ordem de gradação (ex: "Eu explicaria que a pomadinha é para fazer o dente dormir, e, caso a criança não se acalmasse, eu falaria com ela, dizendo que ela já é grandinha para fazer isso"); e (c) Pouco específico na explicitação de suas ações (ex: "Conversaria").

A análise detalhada indicou que $91 \%$ de respostas foram classificadas como a ou b, trazendo descrições específicas de uma ação (a) ou de seqüências de ações a serem realizadas (b). Um percentual de $9 \%$ de respostas foi caracterizado como pouco específico (c). Assim, considerou-se que o questionário suscitou respostas à questão sobre formas de lidar com a situação problema que, em sua grande maioria, foram bastante completas, de forma a permitir uma análise de conteúdo baseada em categorias.
Dessa forma, considerou-se que a análise foi indicativa de alto grau de compreensão do questionário pelos respondentes, e esse foi considerado um instrumento eficiente para obtenção dos dados pretendidos, a saber, a autoconfiança de estudantes de Odontologia para lidar com situações problema no atendimento odontopediátrico, e sua descrição de soluções propostas para lidar com essas situações.

Este trabalho se insere na interface das áreas de Psicologia, Educação e Odontologia. O conhecimento sistemático sobre como alunos lidam, percebem e aprendem estratégias de manejo, é uma área importante para o aprimoramento do ensino em Odontologia, e por que não para as outras áreas da Saúde. Pesquisas como as de York, Mlinac, Deibler, Creed e Ganem (2007), Rubin, Rustveld, Weyant e Close (2008) e Kalwitzki (2005) apresentam estratégias viáveis para compreender o contexto de atendimento odontológico, o emprego de estratégias comportamentais e a aplicação de procedimentos formais de ensino (por exemplo, com o uso vídeotaipe), assim como demonstram a preocupação de produzir conhecimentos, técnicas e instrumentos que auxiliem a avaliação da formação aos alunos de Odontologia.

O presente trabalho contribui nesta sistematização do conhecimento sobre estratégias e ensino de alunos. A aplicação de tal questionário permite mapear áreas de competência e de dificuldades dos alunos, norteando o planejamento curricular, na área das relações entre dentista e cliente, e, mais especificamente, no que se refere a crianças que apresentam problemas de colaboração/participação durante o atendimento odontopediátrico.

\section{Referências}

Ambrosano, G. M. B., \& Moraes, A. B. A. (1999). Ability of dentists in children management. In 77th General Session of the IADR, Journal of Dental Research, 78, 242.

Cardoso, C. L., Loureiro, S. R., \& Nelson-Filho, P. (2004). Pediatric dental treatment: manifestations of stress in patients, mothers and dental school students. Brazilian Oral Research, 18, $150-155$.

Issáo, M., \& Guedes-Pinto, A. C. (1999). Conduta em relação à criança para tratamento odontopediátrico. Manual de Odontopediatria. (10 a ed.) São Paulo: Ed Pancast.

Kalwitzki, M. (2005). Self-reported changes in clinical behaviour by undergraduate dental students after video-based teaching in paediatric dentistry. European Journal of Dental Education, 9, 108-14.

Koch, I. V., \& Travaglia, L. C. (2004). A coerência textual. São Paulo: Ed. Contexto.

Milgrom, P., Weistein, P., \& Getz, T. (1995). Treating fearful dental patients. Washington: University of Washington in Seattle.

Moraes, A. B. A., Batista, C. G., Lombardo, I., Horino, L. E., \& Rolim, G. S. (2006). Verbalizações de alunos de odontologia sobre a inclusão social de pessoas com deficiência. Psicologia em Estudo, 11, 607-615.

Newton, J. T., \& Sturmey, P. (2003). Students' perceptions of the acceptability of behaviour management techniques. European Journal of Dental Education, 7, 97-102. 
Rubin, R. W., Rustveld L. O., Weyant R. J., \& Close J. M. (2008). Exploring dental students' perceptions of cultural competence and social responsibility. Journal of Dental Education, 72, 1114-21.

Wright, G. Z. (2000). Controle psicológico do comportamento de crianças. In R. E. McDonald \& D. R Avery (Eds.), Odontopediatria. ( $7^{\mathrm{a}}$ ed.) Rio de Janeiro: Ed Guanabara Koogan.

York, K. M., Mlinac, M. E., Deibler, M. W., Creed, T. A., \& Ganem, I. (2007). Pediatric behavior management techniques: a survey of predoctoral dental students. Journal of Dental Education,

Recebido em 29.07.2009 $7,532-539$

\section{Jornada Catarinense de Psiquiatria "Saúde Mental: da evidência científica a prática clínica"}

03 de Dezembro de 2011

Florianópolis, SC, BR 